\title{
On the innovation mechanisms of fintech start-ups: insights from Swift's innotribe competition
}

Article

Accepted Version

Gozman, D., Liebenau, J. and Mangan, J. (2018) On the innovation mechanisms of fintech start-ups: insights from Swift's innotribe competition. Journal of Management Information Systems, 35 (1). pp. 145-179. ISSN 0742-1222 doi: https://doi.org/10.1080/07421222.2018.1440768 Available at https://centaur.reading.ac.uk/74122/

It is advisable to refer to the publisher's version if you intend to cite from the work. See Guidance on citing.

To link to this article DOI: http://dx.doi.org/10.1080/07421222.2018.1440768

Publisher: Taylor \& Francis

All outputs in CentAUR are protected by Intellectual Property Rights law, including copyright law. Copyright and IPR is retained by the creators or other copyright holders. Terms and conditions for use of this material are defined in the End User Agreement.

www.reading.ac.uk/centaur 
Central Archive at the University of Reading

Reading's research outputs online 


\title{
ON THE INNOVATION MECHANISMS OF FINTECH START-UPS: INSIGHTS FROM SWIFT'S INNOTRIBE COMPETITION
}

\author{
Daniel Gozman (corresponding author) \\ University of Sydney \\ c/o Henley Business School \\ Greenlands, Henley-on-Thames RG9 3AU, UK \\ Email: d.gozman@henley.ac.uk \\ Jonathan Liebenau \\ London School of Economics and Political Science \\ Houghton St., London WC2A 2AE, UK \\ Email: j.m.liebenau@1se.ac.uk \\ Jonathan Mangan \\ Henley Business School \\ Greenlands, Henley-on-Thames RG9 3AU, UK \\ Email: jonathan.mangan@pgr.reading.ac.uk
}

Last revised: October 29, 2017

\begin{abstract}
The emergence of nascent forms of financial technology around the globe is driven by efforts to deconstruct and reimagine business models historically embedded within financial services. Entrepreneurial endeavors to this end are diverse. Indeed, the propensity towards complexity across the fintech landscape is considerable. Bridging as it does a diverse range of financial services, markets, innovations, industry participants, infrastructures and technologies. This study aims to improve the comprehension of the global fintech landscape. It is based on the analysis of start-ups who participated in SWIFT's Innotribe competition over a three-year period. We used cluster analysis to group 402 fintech start-up firms, and then selected representative cases to create a foundational understanding of the structure of the fintech landscape. We found that six clusters capture the variety of firms and their activities. The main findings of this work are: (1) the development of fintech clusters to classify core services, business infrastructures and underlying component technologies, which characterize the fintech landscape; (2) an analysis of how fintechs synthesize different technologies to restructure and coordinate flows of financial information through competitive and cooperative mechanisms of disintermediation, extension of access, financialization, hybridization and personalization; (3) an analysis of related strategies for value creation connected with the competitive and cooperative mechanisms that were identified. Collectively, our results offer new insights into the diversity and range of emergent innovations and technologies which are transforming the financial services industry worldwide.
\end{abstract}

Keywords: Business models, cluster analysis, data analytics, financialization, fintech start-ups, SWIFT Innotribe, technology ecosystems, technological innovation, value propositions.

Acknowledgments. We thank the SWIFT Institute for the collaborative efforts of their team towards data collection. We are also grateful to Rob Kauffman, Chris Parker, Peter Gomber, and Bruce Weber, as well as the anonymous reviewers and editorial assistant for their guidance and assistance in refining our work. 


\section{BRIEF BIOS}

Daniel Gozman is a Senior Lecturer at the University of Sydney and a visiting academic at Henley Business School at the University of Reading. He holds a PhD. in Information Systems and Innovation from the London School of Economics. He is a fellow of the Higher Education Academy, a member of the Association of Information Systems, and holds professional membership with the BCS Chartered Institute for IT. He is a member of the British Standard Institute UK mirror committee to ISO for blockchain and distributed ledgers. He is a co-investigator on a UK Engineering and Physical Research Science Council grant to explore blockchain technology for algorithmic regulation and compliance. He is the winner of two grants from the SWIFT Institute. His research articles have appeared in the Journal of Information Technology, Journal of Enterprise Information Management, and European Journal of E-Practice, among others. He has presented in conferences on fintech, policy and the law, and contributed to articles in Sunday Times, Vice Magazine and Computer Weekly.

Jonathan Liebenau is Associate Professor (Reader) in Technology Management at the London School of Economics, and an associate of the Columbia Institute for Tele-Information, Columbia University. His was educated in science and technology policy, the history and sociology of science, and technology and medicine at the University of Rochester and the University of Pennsylvania, where he earned his Ph.D. in 1981. His research focus is on blockchain, fintech and regulation, digital economy in China, and competition in operating systems - all with grant funding. He has consulted and researched for leading ICT companies, and has been engaged with the European Union and the OECD, among others. He is a frequent keynote speaker in leading international IT, telecom and policy conferences. He is author or editor of twelve books and many articles on innovation studies, Internet policy, and the history of technology. His research has appeared in: Decision Support Systems; Journal of Information Policy; Information Systems Journal; Accounting, Science and Public Policy; Management and Information Technology; Journal of Information Technology; and interdisciplinary outlets.

Jonathan Mangan has had a distinguished career as an engineer and product lifecycle management consultant. His work with industry innovators and start-up companies has resulted in published patents and collaborations for medical Ph.D. research and product designs. His experience includes chairing a public/private start-up support organization that provided mentoring for SMEs and achieved two successful rounds of government funding. In addition to his business activities, he is currently completing a doctorate at the Henley Business School on the new technologies that are behind the recent rise of high-reliability organizations such as fintech firms. 


\section{INTRODUCTION}

The shifting landscape of financial markets has challenged conventional thinking about relationships among technology, business models and financial services. The fintech community ${ }^{1}$ is emerging in association with incumbent industry participants upon whom they rely for staff, knowhow, business infrastructure and, crucially, as customers. Fintech firms are distinguishable from the legacy incumbent financial services companies by their use of technology to reimagine the products, services and capabilities of the traditional financial services sector. The fintech revolution is characterized by the application and synthesis of technological capabilities to reduce barriers to entry and allow newcomers to insert themselves into value chains, as providers of innovative products and services. The outcome of this restructuring is that different technologically-enabled mechanisms for competing and cooperating with incumbents are emerging in tandem with new strategies for value creation.

Information systems (IS) researchers have long observed how the introduction of new technological forces can restructure established and previously stable fields [42]. Exogenous shocks, such as the 2008 financial crisis have the potential to destabilize fields and create significant change. One such effect of the crisis was to stimulate self-doubt within the financial community, making it amenable to change. Another came about as bank staff lost their jobs, which pushed many people towards entrepreneurial activities [21]. Indeed, the financial crisis precipitated complex structural changes to economic environments while digitization has made financial information more readily available, programmable, communicable, associable and traceable.

Within financial organizations, technology is extensively used across the value chain, and is a driver of innovation within financial services. Yet the academic community has provided little insight into the landscape of recent innovations related to the Fintech Revolution [40]. In bridging this gap, we build upon the view that a financial technology ecosystem ${ }^{2}$ is composed of interrelated technolo-

${ }^{1}$ Fintech, for this study, refers to the new wave of start-ups which have emerged in the wake of the financial crises, and have focused on reinterpreting and transforming traditional financial services, through new forms of technological innovation.

${ }^{2}$ The term financial technology refers to all technologies which underpin financial activities. 
gies with specific roles, that is in a continual state of transformation aimed at improving product, process and managerial performance [2]. Within the ecosystem, innovation is facilitated as new technologies are introduced and new technological combinations enable business models to evolve, while correspondingly unsuccessful or outdated combinations of technological innovations and related business models have their value eroded to the point of irrelevance and extinction [3].

Our study addresses empirical questions about the emergent nature and dynamics of technological innovation across the fintech landscape. It is based on a large dataset of 402 fintechs collected for the years, 2013 to $2015^{3}$ as part of a global start-up competition operated by SWIFT: the "Innotribe Start-Up Challenge". ${ }^{4}$ It encompasses a wide range of rich qualitative and quantitative data regarding fintechs from across the globe. SWIFT launched the Innotribe initiative in 2009. The Innotribe website describes its purpose to connect, “people, networks and ideas, bringing together global innovators and investors, strategists, and influential decision-makers from leading financial institutions across the globe" and as the "leading global start-up competition, connecting the financial services industry with 650 FinTech start-ups around the world and reaching over 4,000 audience members through global showcases and networking events" [29, p. 1].

Our motivation, in drawing upon this unique dataset, is to go beyond studying a specific technology or sector of the financial services industry. Instead, we aim to holistically investigate the fintech landscape. We have studied the Innotribe population of fintech firms in terms of the business models they adopt, the technologies they utilize and the value they deliver to answer questions about the ways in which the fintech landscape is challenging and disrupting historically embedded strategies and practices. Consequently, we adopt the following research question: How is the emerging fintech landscape characterized in terms of competition and cooperation with other industry participants and by related strategies for value creation?

The paper relates this work to previous studies and relevant theory in the next section. Following a discussion of our data and the methodology of its analysis, we offer multiple cases on fintech

\footnotetext{
${ }^{3}$ From 2016 the Innotribe competition focused on specific geographical areas and so became less global.

${ }^{4}$ Society for Worldwide Interbank Financial Telecommunication (SWIFT) is a global financial messaging infrastructure provider, founded in 1973 and headquartered in Brussels. SWIFT operates the primary digital communications channel for financial institutions engaged in correspondent banking.
} 
start-ups in six discrete clusters that participated in the entrepreneurial business development competition of SWIFT Innotribe. Our discussion of these cases leads to our findings regarding mechanisms of competition and cooperation and strategies for value creation.

\section{PRIOR LITERATURE AND THEORETICAL UNDERPINNINGS}

\subsection{Reconstructing the Flow of Financial Information for Value Creation}

As others have observed, a multi-disciplinary and multi-level analysis is particularly appropriate for understanding the wide range of technological innovations and relationships and the interdependencies manifest in financial technologies [27]. A consistent theme in the financial technology literature is competition and cooperation between new entrants and incumbents [35]. The digitization of financial services, may redirect flows of financial information away from incumbents and traditional infrastructures and thereby create instability to established ecosystems. For example, peer to peer payments allow individuals to transfer funds directly between themselves and so bypass payments infrastructures collectively developed and funded by incumbent banks. The introduction of such innovations is thus impacting established competitive and cooperative dynamics between industry participants [26]. Indeed, previous work has shown how financial incumbents have often failed to collaborate with firms which fall outside traditional industry boundaries (e.g., telecoms) [13]. We rest this research on studies of how financial information usage has changed with the advent of digital technologies and associated business models. Our literature draws upon theoretical perspectives which outline how the coordination and structure of information pathways underpin the operation of financial services and markets [25]. Indeed, financial services are characterized by asymmetric information and understanding which is the basis on which many financial organizations compete [24]. Recent technological innovations reconstruct and redirect the flow of financial information and so facilitate new competitive and cooperative mechanisms through which value is created and dispersed [16].

Redirecting Financial Information Flows. New innovations may reflect and emulate the characteristics and discipline of traditional financial markets through channeling financial information to consumers in new ways [31]. Van den Zwan [46, p. 99] observes the financialization of daily activities and addresses the diversity of ways in which finance is becoming entangled in everyday life as, " $a$ 
decentralized form of power... exercised through individuals' own interactions with new financial technologies and systems of financial knowledge." For example, crowdfunding platforms harness the power of social media to allow private individuals to collectively finance entrepreneurial activities. Investors in crowdfunding campaigns receive assets in return for funds, which provide regular interest payments, or equity in the organization being funded [19].

The restructuring of payments ${ }^{5}$ flows has also facilitated the growth of e-commerce activity [34] and the adoption of online banking [21]. Other forms of technology have created new flows of financial information including messaging protocols, standards and networks. For example, open APIs have the potential to facilitate banking-as-a-platform innovations, and so create more personalized customer-centric experiences [48]. Recently, innovations supported by card payment services, mobile phones and location-based services have enabled entrepreneurs to challenge long-established banking models and infrastructures. Two distinct operating models for payments have emerged since the 1980s [32]. The first relies upon embedded and historically structured information pathways controlled by established players and the second disintermediates existing information channels entirely [6]. The most radical payments innovations such as peer-to-peer networks and cryptographic currencies have been driven partly by frustration arising from shortcomings in existing payment arrangements built upon cumbersome legacy systems. Blockchain, also known as distributed ledger technology (DLT), is the basis for cryptocurrencies by allowing for an encrypted record which is decentralized or distributed, permanent yet amendable, and is, therefore, theoretically more transparent and easier to audit [39].

De-Obfuscating Financial Information Flows. Various studies have highlighted how new technologies are increasing transparency and reducing obfuscation of information [47]. Financial innovations that build on new technological platforms are breaking down traditional barriers of geography, access and asymmetric information. Key technological developments include cheaper storage,

\footnotetext{
${ }^{5}$ We view payments as a service innovation which operates at the consumer/corporate/merchant levels. We distinguish fintechs focused on payments services from payment markets infrastructure providers such as "Target 2" which is operated by the European Central Bank and 19, at the time of writing, national central banks within the European Union.
} 
quicker and more secure networks, and the use of the cloud, as well as the development of social media [10]. A related stream of activity has focused on bringing new financial products and services directly to the private consumer or business, often through social media and so disintermediate incumbent firms' traditional arrangements for provisioning finance. Crowdfunding platforms partly exist because it is difficult for early-stage entrepreneurs to raise external finance via either equity or debt because of problems of asymmetric information between borrowers and lenders leading to adverse selection [9].

A further body of literature addresses technologies which facilitate the buy-side of financial services, the buying and selling of assets for investment purposes through capital markets. A few studies dating back to the work of Zuboff [50] have addressed the informatization and automation of activities across different operational streams, including portfolio management [43] and integrating order-driven trading systems into quote-driven markets [41]. More recently studies have addressed highfrequency trading and the automation of investment activities [30]. Scholars have also focused on studying fintechs which provide alternatives to traditional vehicles for financial advice, by drawing upon social media and the crowd to inform investment decision-making [36].

Increasing technological innovation has led to the widening of regulators' remits to include peer-to-peer lending for example. A related strand of literature addresses how responses to the financial crisis have resulted in heightened levels of regulatory supervision espoused as necessary to protect consumers and guard against systemic risk to wider economies. Related obligations requiring increased levels of transparency and reporting across financial markets and banks' operating practices are rationalized as necessary to increase accountability and reduce potential moral hazards arising from information asymmetries [23]. Correspondingly, technologies which collate, structure and disseminate such information have an important role to play in ensuring compliant behaviors and in demonstrating robust and fair practices. Through the automation of governance, risk and compliance (GRC) activities new regulatory technologies or regtechs aim to automate obligations regarding the collation and reporting of financial information to reduce the burden of post-crisis obligations on regulated fintechs (e.g., challenger banks or robo-advisors) and incumbents alike [7]. Such technologies allow firms to remain compliant and operate in regulated markets and so underpin the viability of the 
firm's business model. Related studies have investigated compliance systems in asset management houses [22] and risk management tools [15]. Other work has focused on regulatory technologies designed for use by the regulators themselves for investigating insider trading and market manipulation [47].

Protecting Financial Information Flows. The security of financial information underpins the sanctity of markets. Cybersecurity includes encryption technologies which enable secure transactions to counter the existential threat to new forms of financial technological innovation, because where systems are not trusted they will not be used [12]. A further strand of financial technology related literature has focused on advanced tools and technology to protect consumers from identity theft, fraudulent transactions and account falsification. Security and privacy are paramount to galvanizing support for nascent forms of digital transactions. Technological solutions that leverage biometrics for fast and robust authentication, coupled with anonymization technologies such as tokenization, are increasingly becoming critical components in creating an environment of trust [44].

In summary, recent technological innovations restructure traditional flows of financial information. Related work has focused on differentiated sectors of finance and underpinning technologies that come under the fintech umbrella. We situate our own study among those which address the ways in which new innovations are influencing and altering channels of financial information. The potential to transform embedded practices through technologically underpinned innovation has vast potential yet is poorly understood by those in the public and private sectors. Our study bridges the gap between discrete sectoral studies and those non-empirical explorations of themes such as investing in fintech start-ups by analyzing the SWIFT Innotribe experience [11].

\subsection{Conceptual Model: Technologically-Enabled Mechanisms of Competition and Cooperation}

Figure 1 depicts our conceptual model which we derive from the literature outlined above. The model and related theoretical constructs guide our research design and interpretations of the Innotribe dataset. In building our model we draw upon Adomavicius et al. [4, p. 782] who note that an "ecosystem view is a useful approach for representing the many technologies and relationships that make up the IT landscape." Proponents of the ecosystem perspective further advocate its usefulness in making technological interdependencies more explicit and highlight their ability to transform existing 
business models [6]. Consequently, we frame our analysis through recent theories of financial technology ecosystems and employ three distinct constructs from these works. [35]. Collectively, these constructs provide a holistic picture of different innovation types which are composite of the financial technology ecosystem [10].

\section{INSERT FIGURE 1 ABOUT HERE}

The first construct is Services, and refers to technology innovations which structure information flows at the intersection between fintechs and consumers of its Services. These technologies provide access to a plethora of financial services and so occupy specific areas of the financial services' value chain, for example, payments services or investment services.

The second construct is Business Infrastructure, and refers to those technological innovations which complement the Service innovations and so coordinate information flows between the front office activities and operational practices assigned to the middle and back-office. Business Infrastructure innovations add further value, often by extending the functionality, improving the performance or facilitating the provision of core Services. Examples include technologies which enable financial education and literacy, often through gamification, and so enhance personal financial management services and those technologies which facilitate an organization's compliance activities, thereby supporting the provision of regulated Services.

The final construct is Components, which refers to the most granular type of underlying technological innovation. Components are the building blocks from which Service and Business Infrastructure innovations are comprised, examples include cybersecurity or big data technologies.

In developing our theoretical arguments, we found these constructs to be useful in understanding the technological interdependencies of new fintech innovations and their ability to transform existing business models. Zott et al. [49, p. 1034] provide a useful summary of the business model concept, suggesting that, "In the technology and innovation management field, the business model is mainly seen as a mechanism that connects a firm's (innovative) technology to customer needs and/or to other firm resources (e.g., technologies)." This functionalist perspective views technology as an external enabler of the business model rather than a composite element of it. And so the core logic of 
a business model instead revolves around its value proposition, and mechanisms of competition, cooperation and ultimately value creation. Central to the business model construct and our theoretical framing is that we attempted to create value through underlying technological mechanisms which act to coordinate the distribution of financial information. Specifically, the synthesis of Service, Business Infrastructure and Component innovations has allowed fintech start-ups to create new technologically-enabled mechanisms. Through these, financial information is structured and shared among the industry participants, including consumers, partners within the value chain, competitors and regulators. In doing so, these mechanisms create new forms of information asymmetries which form the basis of competition and cooperation that are redefining markets for financial services [5].

\section{DATA, METHODS AND ANALYSIS}

Our analytical method was inductive, multistage and iterative in its approach [17]. To gain insights into the technologies and business models which collectively characterize the fintech field, we selected a mixed methods approach. First, to cluster the 402 cases of Innotribe competition participants and then systematically to analyze each cluster's constituent cases. In this way, we were able to analyze a large dataset of firms both qualitatively and quantitatively. To participate in the Innotribe competition, fintech start-ups were required to submit an application and registration form, a pitch deck of slides, and a pitch video. These documents provide deep insight into each participating firm. Table 1 summarizes the data sources available for each case in the Innotribe data set. (See Table 1.) Table 2 provides some descriptive stats which provide insight into staffing, projected revenue, investment and number of customers (See Table 2).

\section{INSERT TABLE 1 ABOUT HERE \\ INSERT TABLE 2 ABOUT HERE}

By combining quantitative evidence with cases, we are able to show how the fintech landscape is characterized through mechanisms of competition and cooperation. The analysis of multiple fintech cases allows a broader exploration of our research question and the theoretical perspectives we have offered. Theory-building through analyzing multiple cases may also yield more robust and generalizable results than a single case [8]. We employed two complementary interpretive methods, 
termed Stages 1 and 2, to group and then analyze fintech firms that entered the Innotribe competition between 2013 and 2015 .

\subsection{Stage 1: Clustering the Innotribe Participants}

In Stage 1, we adopted a cluster analysis to group the Innotribe participants. Clustering methods have been applied in a variety of research settings within strategic management and IS studies, and it is appropriate for this population of fintech firms [33]. Cluster analysis refers to a branch of descriptive and exploratory statistical techniques which seek to group similar cases. This allows us to focus on relationships among cases rather than relationships between variables. Groups and related boundaries between the cases are not prescribed a priori, but are instead defined according to patterns found in the case's attributes. The key outcome is that the cases within the cluster have a greater degree of commonality than those outside [18].

The input variables used for the cluster analysis were derived from SWIFT's interpretation of the fintech landscape. To characterize each fintech start-up participating in the Innotribe competition SWIFT derived 17 classifications of different types of innovation with each participating fintech selfselecting a maximum of three classifications to describe their business. The definition of each classification was derived by SWIFT's Innotribe team and built upon the organization's extensive knowledge of financial technologies and related innovations. The classifications were refined as the competition matured and SWIFT's understanding of the fintech landscape further developed. In collaboration with SWIFT's Innotribe team, we conducted an exercise to align, consolidate and refine the classifications $^{6}$. Consequently, we were able to develop a consistent set of classifications to cluster across the three years of Innotribe data that we obtained.

Throughout this process, we were careful to keep SWIFT's initial descriptions of the classifications as a guide. We were then able to link each of SWIFT's classifications to one of three innovation types embedded in our conceptual model: Services, Business Infrastructure and Components. We

\footnotetext{
${ }^{6}$ The reader should note the difference between classifications, which were directly obtained from SWIFT, versus clusters, which were the outcome of cluster analysis that we conducted on the basis if the SWIFT classification data. The terms are not interchangeable, and we have been careful to ensure that the remainder of this article adheres to this difference.
} 
were thus able to validate the classifications through prior theorizations of financial technology ecosystems. Table 3 highlights the classifications that we refined and then employed in our cluster analysis, their innovation type and SWIFT's original classification. (See Table 3).

\section{INSERT TABLE 3 ABOUT HERE}

The classifications were selected as input variables for our cluster analysis to group the Innotribe participants around the categories self-selected by the firms to describe their businesses. In this way, we employed cluster analysis as an exploratory technique to investigate our rich data set of 402 fintech start-ups. We employed different clustering algorithms as part of a research process that involved a mixture of exploratory and confirmatory exercises to find the best possible clustering [38]. Both distance-based and model-based clustering algorithms were applied, ${ }^{7}$ and an iterative process identified meaningful clusters that illustrated the characteristics of the Innotribe competition and participant fintech cases.

An important challenge in employing a rigorous cluster analysis is knowing when the clusters are real, and not superficially imposed by the method employed. Consequently, an important step in our research design involved validating the meaningfulness of the clusters through reviewing the outputs of five different clustering models with members of SWIFT's Innotribe team. The characteristics of each cluster and their validity were assessed in terms of the most prevalent classifications within each cluster and their relationship with the three elements of the financial services' ecosystem. Thus, we were guided by our conceptual model and theories for interpreting and assessing different clustering models.

It has been suggested that social scientists have an important advantage in validating the output of clustering methods, as often it is possible to approach individuals operating within the research setting and verify the meaning of the clusters and their constituent cases [45]. Over the course of our research, we conducted 19 interviews at different stages of the data analysis with SWIFT's Head of Innotribe Innovation Programmes and Innotribe Start-up Challenge Producer. Our validation process

\footnotetext{
${ }^{7}$ Ultimately, a model based approach was chosen as we found this provides a more stable and consistent interpretation of scaled and categorical variables (the classifications) and is less sensitive to noise and outliers in the dataset. This approach allows cases (individual fintech firms) to be classified into clusters using model-based posterior membership probabilities estimated by maximum likelihood methods [18].
} 
culminated in a presentation of the final six clusters and related illustrative cases to the SWIFT Institute's Director and Assistant Director to discuss and validate our final analysis.

\subsection{Stage 2: Interpreting the SWIFT Innotribe Cases}

The next stage after validating the clusters was to select cases of fintech firm's which are representative of the six discrete clusters. Adopting a case study approach has previously proven fruitful in understanding the relationships between changes and innovations in financial activities and technology, specifically in the areas of insurance [28] and capital markets [1]. Once we had assigned the Innotribe participants to membership of a cluster, an analysis of each case was performed by reviewing the data sources held for each case. (See Table 1.) The richness of the dataset informed the selection of representative firms within each cluster that were subject to further rigorous coding. To select illustrative cases for each of the clusters we adopted a typical case-purposive sampling strategy [14]. This sampling strategy required a search for information-rich cases representative of the combinations of classifications characterizing each cluster.

Data analysis of each of the cases was conducted through well-established interpretive methods for reviewing data through the recursive identification of patterns, first through categorization and then abstraction [20]. To provide consistency in our analysis, we structured a template, which defined specific areas of analytical focus to be applied to all cases. The structure of the template was derived from our conceptual model and included sections for summarizing the mechanisms of competition and cooperation as well as value creation and underpinning technologies. In this way, we were able to ensure a systematic and consistent approach to our interpretations of each case. Table 4 provides an example of two case summary tables derived for the Payments Cluster (Cluster 1), and illustrates how means of value creation, competition and cooperation were derived from the cases. (See Table 4.)

\section{INSERT TABLE 4 ABOUT HERE}

In further developing our analytical method we adopted a two-cycle approach to thematically coding and categorizing the case data. The first cycle adopted a descriptive coding approach for summarizing segments of data. This method is appropriate for inductive studies and requires the association of a code to a segment of data representing a summary of a granular activity or practice. For ex- 
ample, "Use of social media for credit scoring" or "Use of big data to collate and present complex financial data" or "Use of bitcoin for remittance payments". The second cycle adopted a pattern coding approach to identify major themes by searching for causes and explanations from the data. Such approaches build on the first cycle of analysis and are "explanatory or inferential codes, ones that identify an emergent theme, configuration or explanation. They pull together material into meaningful units of analysis" [37, p. 69] By iterating across levels of abstraction, we were able to inductively derive various mechanisms of competition and cooperation. Examples include, "Financial inclusion (extending access)", "Disintermediating financial advisors" and "Disintermediating payment networks." Scope, depth and consistency were achieved by discussing key concepts, constructs and terminology with SWIFT's Innotribe team, and triangulating the findings across secondary data sources in Table 1.

\section{FINDINGS AND ANALYSIS: CHARACTERIZING THE FINTECH LANDSCAPE}

The clustering of the Innotribe dataset has allowed a rich analysis of 402 fintech start-up cases. Our interpretation of each cluster is rooted in the literature we outlined, and the understanding that different elements of the financial technology ecosystem collectively form innovative approaches to financial services. Table 5 outlines the characteristics of the fintech landscape as reflected by the Innotribe competition. (See Table 5.)

\section{INSERT TABLE 5 HERE}

Each cluster is chiefly characterized by fintech start-ups innovating around a core Service. Firms participating in the Innotribe competition selected a maximum of three classifications. So, in addition to being associated with a core Service, the firms in each of the six clusters were also associated with other classifications. Often fintech entrepreneurs sought to create value by engaging with innovations which complement and support the delivery of core financial services. Those who selfselected classifications that fall inside the Business Infrastructure innovation type, therefore, are either providing additional value to the core Service or providing an innovation which facilitates its delivery. In some clusters, only one Business Infrastructure classification was found to dominate, except in Clusters 2 and 6, for which two were significant. The third element, Component, refers to innova- 
tions which underpin the other two elements. All three of these innovation types were found to be significant to some degree in each cluster highlighting how the fintech landscape is underpinned by technology innovations including the cloud, blockchain, cybersecurity and big data analytics. In the following analysis, we outline specifically how each of these three innovation types and related more granular classifications have come to characterize the fintech landscape.

\subsection{Core Service Innovations}

Payments. Cluster 1 is chiefly characterized by firms that selected the Payments classification. Payments-related innovations contribute to growth in electronic and mobile commerce and are drivers of socioeconomic development in emerging economies. One important aspect of the payments sector, remittances, allows expatriates to send money to their home country and for individuals to pay bills using mobile devices when internet access is limited. Bitspark is a cash in, cash out remittance platform established in 2014 in Hong Kong. The business facilitates remittance payments in emerging markets and Asia estimated at $£ 280 \mathrm{bn}, 40 \%$ of which was supported by money transfer operators (MTOs). Bitspark's uses of blockchain and bitcoin reduce the costs for MTOs who enable such customer-to-customer transfers. Where MTOs are part of a larger payment network they can pay up to $80 \%$ of their commissions to the network provider, usually a banking incumbent, and these costs are passed on to the consumer along with high upfront set-up costs. The software provided by banking incumbents is also restrictive, often allowing limited currency and withdrawal options and only providing a remittance corridor between two countries. This results in the MTO having to use several platforms to facilitate a transfer, which slows the process and increases cost.

Bitspark allows MTOs to change money into cryptocurrencies and then transfer them across the bitcoin network instantly to another MTO located in a different part of Asia where the bitcoins are then transferred back into cash. Bitspark also runs a bitcoin exchange in tandem with the remittance business. The remittance payments help provide volume and liquidity on the cryptocurrency exchange and the exchange provides a better spread for remittances and greater capacity for payments. Overall, the value is created through charging lower fees than incumbents while eliminating commissions to incumbent payments infrastructure providers.

Another exemplary case of the Payments Cluster is Madfoo3at.com, an e-payments service 
company founded in Jordan, supported by the government seed investment program, Oasis500, and partnering with the Central Bank of Jordan. Madfoo3at.com provides services to banks and merchants through technologies that allow consumers to pay bills electronically. Banks, and merchants as billers register once to allow their customers to pay using the banks' electronic channels. Merchants pay a fee per transaction and Madfoo3at.com shares the fees with the banks, thereby creating an extra stream of revenue. They create value by facilitating online billing, where most bills in the Middle East and North Africa are paid by cash into banks. For consumers, this innovation eliminates regular trips to the bank, often with long queues. For banks, cash-based processes increase human error and fraud while requiring banking organizations to maintain more staff and adopt manual processes.

Investment and Asset Management. Cluster 2 is predominately characterized by firms focused on the buy-side of capital markets. These fintechs typically concentrate on investment advice and portfolio management services. An exemplary case in this cluster is Stockpot. Founded in 2013 in Sydney to provide automated investment advice using an online platform. Stockspot extends investment activities among people who do not wish to pay fees normal for financial advisors. Investments are made in low fee exchange-traded funds (ETFs) across asset classes which include equities, fixed income, and gold. Investors may go online and fill out a risk profile which is then associated with a mix of funds that match their long-term aspirations, liquidity needs and risk appetite. Algorithms monitor and rebalance the account as deemed necessary and reinvest dividends. Customers may also personalize their portfolios with investment themes. Fees are paid either by a monthly amount for small investors or an annual fee, plus an asset-based fee of .066\%. The platform integrates with accounting software to reduce accountant expenses and operates in ways similar to other robo-advisors, such as Wealthfront, and Betterment in the U.S., Nutmeg in the U.K. and Quirion in Germany. The value is created by low fees for high volume transactions, some of which reach new markets, carried at low cost due to automated advising and algorithmic portfolio management.

Finance and Credit Management. Cluster 3 is populated by firms innovating around traditional lending and credit services (including provisioning and management) for consumers and businesses. One exemplary case is PremFina, which supplies insurance brokers (e.g., for car insurance 
firms) with software and financing to manage the sale of insurance policies to consumers and businesses. This is achieved through PremFina lending the broker the necessary funds to pay the insurance company for the policy immediately. The broker can then "white label" the policy to the customer. The collateral for the loan is the insurance policy itself. This approach saves brokers from handing over their customer relationships to the insurance company. So they merely act as introducers, by providing brokers with an in-house capability to directly finance their customers' insurance premiums. This approach also allows the customer to pay the broker for the insurance in installments rather than in full. Value is created by Premfina inserting itself into the value chain, brokers can offer their own branded insurance premiums, creating new regular revenue streams for the company and thus allowing them to directly manage the customer life-cycle. Ultimately, this innovation allows brokers to offer its customers more flexible insurance terms and rates and to control the customer experience, which in turn allows the broker opportunities to cross-sell and up-sell other financial services.

A further example of a case which represents Cluster 3 is Trusting Social based in New York. It uses data analytics applied to social networking and mobile telephone data to provide risk profiles for lenders and insurers. The firm provides real-time, scalable analysis and online access, and aims to circumvent incumbent credit scoring agencies. Trusting Social exemplifies fintech companies that bring together expertise in data analytics, social networking, Internet scraping and financial services processes to provide a core Service that had previously been done with limited sources of evidence (e.g., credit history), involved analogue processing (e.g., form filling) and a narrow scope of interpretive techniques (e.g, risk profiling). Value is created by automating risk profiling for those without credit scores to extend the market for lending and insurance.

Microfinancing and Crowdfunding. Fintech start-ups within Cluster 4 are focused on the provision of untraditional lending services with funds provided by non-banking entities. Fintech start-ups in Cluster 4 often draw from the crowd and social media to fund small business loans, student loans, and property mortgages, for example. Firms within this area include debt (e.g., Zopa, Lending Works and $\underline{\text { Ratesetter) }}$ and equity-based (e.g., Crowdcube and Seedrs) crowdfunding platforms. One illustrative case employs the crowd to fund business inventories. Kickfurther of Boulder, Colorado is an online marketplace where crowdsourced backers can fund inventory for businesses. The firm aims to 
solve difficulties new business have in sourcing raw and intermediate materials. Backers can fund the inventory for businesses and benefit from their success. When the inventory sells, the backers earn a consignment profit rather than an investment return. The firm is based on a large global market (estimated by Kickfurther to amount to US $\$ 1$ billion) served by a range of alternatives but where no single competitor has majority market share. Value is created by providing businesses needing inventory with an alternative means of financing and funders access to a new form of collateralized investment.

Some of the fintech firms in Cluster 4 aim to fill gaps in lending left by traditional financial incumbents by providing credit to those individuals and organizations which traditionally have struggled to get credit (e.g., for microfinancing). For example, by focusing on the financial well-being of employees, London-based Creditable makes it feasible for employers to lend through payroll deductions or other means. Artificial intelligence tools guide employees through their financial status and assist them in making decisions. Creditable can also provide information to third-party lenders and borrowers about the financial conditions of borrowers. Their analytical tools allow for monitoring worker financial access in relation to productivity, employee turnover and other measures. While this form of lending to employees has been applied by others, Creditable has made it a distinct specialty, separate from in-house human resources departments. Value is created by tapping many low-risk customers, the market is extended and service offerings provided to employers to boost employee wellbeing.

A further example of microfinancing, within Cluster 4, is the Cape Town-based Lulalend, an online provider of short-term loans for businesses (e.g., 6 or 12 months) to SMEs in Africa. Analytics allows the organization to automate the credit application and assessment process thereby, providing a decision on the loan within minutes and supplying the agreed-on funds soon after, possibly within twenty-four hours. Another example, ZAQ Finance, also based in Cape Town, works with employers to help their employees get access to more affordable credit services. Their goal is to increase financial literacy and make financial services more accessible and affordable to low-income markets in Africa. Initially, they have focused their efforts on the agricultural sector. Through the automation of the lending process, they are able to significantly reduce their costs and correspondingly the cost of credit by working with farmers at the group level. They offer Services around consolidating existing debts, 
providing emergency loans and credit for white goods. They also provide debt management help.

New Banking. Cluster 5, the New Banking Cluster, is predominantly characterized by firms innovating and reimaging traditional banking services for consumers and businesses. One such firm is Magna/Btc.sx, launched in 2013 they offer mainstream and secure banking services for cryptocurrencies. There are two sides to the business, bitcoin interest-bearing savings accounts and retail trading accounts. Those wishing to trade bitcoins "borrow" them from those who hold them, in savings accounts and then take long and short positions. In doing, so they pay an interest rate which is passed back to the saving accounts holders. Magna/Btc.sx views its target market as both in developed and developing countries and offered 2.35\% fixed interest rate until October 2016, then reduced to $1.28 \%$ till June 2017. Their main competitors are other fintechs focused on bitcoin wallets and trading, such as Coinbase or Bitfinex. They charge no daily management fees for savers but instead charge traders an open and close fee on each position and a funding fee for borrowing the bitcoins. There is no minimum deposit for savers.

One example of innovating around traditional credit offerings is Happay, which furnishes firms with Happay's own business expense card for employees. Happay allows the firm to control where the company's money is spent by defining spending policies, setting spending limits, configuring notification and allowing the firm real-time visibility into company-wide expenses before employees have submitted their expense reports.

Personal Financial Management (PFM). The final cluster, Cluster 6, refers to activities focused on managing individual and family finances, tax planning, bills and invoicing for the self-employed and micro/small businesses. One case which well exemplifies this cluster is MaxMyInterest, operated by a New York investment firm, which helps individual investors earn more on Federal Deposit Insurance Corporation insured bank deposits by linking a users' existing checking account to higher-yielding online savings accounts. Periodically, the system automates the relocation of funds among the user's accounts to maximize yield and ensure all funds remain within insurance levels while maintaining a desired checking account balance. They claim that members typically earn $0.90 \%$ to $1.10 \%$ more than they would at traditional banks.

Another New York-based firm, Debitize, aims to help consumers utilize and manage their 
credit cards more efficiently by automatically transferring funds from a user's checking account to cover credit card purchases. A user creates an account and connects their bank and credit card accounts by providing login credentials. Once a credit card is linked, purchases on that card will trigger a daily debit from the user's bank account to their Debitize account for the same amount. These funds will then be used to pay off the credit card at the end of the billing cycle. This process allows the customer to use a credit card with the cash flows of a debit card and so to enjoy the advantages of credit cards, including rewards and cash back, and the ability to build better credit.

The firm also offers a premium service to improve credit scores by automatically paying off the balance more frequently if necessary to ensure credit utilization ratios remain within the ideal range of 20-30\%. Our final example is Budget Insight, based in Paris, which uses an automatized interface to gather a users' bank accounts in one place and then analyze where their money is spent. The software automatically categorizes expenses and is able to predict the user's balance and expenditure and offer relevant financial advice.

\subsection{Business Infrastructure Innovations}

Merchants and Corporations Support. The second element of the financial services ecosystem refers to Business Infrastructure innovations which complement and support core Services. Many firms in the Payments Cluster (Cluster 1) distinguished themselves by also selecting the "Merchants and Corporations Support" classification. These fintechs offer payment-related services to compliment a financial incumbent's existing offerings to merchants and corporations. Examples include firms such as Swish/Truevo from Malta or Activa from Berkeley, California, which provide mobile payments platforms to banks, payment service providers and telecommunication companies and so allow their customers (e.g., merchants and corporates) to accept payments across various channels (e.g., SMS, interactive voice response, mobile phones, near field communication, QR codes, and the Internet).

Firms identifying with the cluster also draw from the close relationship between payments innovations and e-commerce operations. Digicash Payment based in Luxembourg focuses on providing a white-labelled mobile payment authorization platform and integrated e-commerce system. By integrating with core banking systems, they aim to facilitate customer centricity and allow incumbent 
banks to offer their merchant clients loyalty program, couponing and direct marketing capabilities based on location, behavior and usage.

Financial Education and Literacy. Cluster 2's core Service (Investment and Asset Management) was complemented by innovations that facilitate simulations and gamification techniques to educate investors and increase financial literacy and ultimately increase levels of engagement. One innovation that seeks to improve the financial literacy of the buy-side of financial services is London based, StockView. Their platform matches investors and equity analysts who supply research online. The value this fintech aims to create is supported by the view that the quality of online equity research has decreased in recent years and that investors' trust in such online reports has consequently waned. StockView allows analysts to create ratings and to assign a buy, sell or neutral label to their chosen stock. The analyst adds a short comment and can also create a discussion article to support their rating. Upon creating a rating, the system will measure the performance of that rating against the market. Based on their stock performance and on the quality of their research, analysts may progress through the platform from "analyst" to "senior analyst" to "vice president". For each stock, the systems aggregate the views of the top-performing analysts into a crowdsourced signal. Analysts are paid only from the subscriptions they receive from investors.

Clearing and Settlement. Cluster 2 is further characterized by innovations which support the exchange of assets once the investment decision has been made. Amongst financial incumbents there has evolved a plethora of disparate settlement networks operating across different asset classes and geographies, often integrated with legacy accounting systems. This has led to data duplication, unnecessary complexity, wasted effort and increased settlement times resulting in higher reconciliation risks and costs. Hyperledger, the winner of Innotribe 2015, aims to overcome these issues by using distributed ledger technology to provide clearing and settlement infrastructure. Their innovation allows for a shared replicated ledger that custodians, banks and regulators can all access in real time, while ensuring that access to trading information is appropriately segregated.

Governance, Risk and Compliance (GRC). Cluster 3 consisted of firms engaged in GRC activities. One such firm is Percentile whose RiskMine platform, aims to provide tier 2 and 3 banks the same analytical sophistication in risk management traditionally available only to the tier 1 financial 
incumbents through their own large and expensive internal risk management function. The technology facilitates advanced value-at-risk (VaR), expected shortfall and hypothetical and historical stress testing calculations, thereby facilitating regulatory calculations and correspondingly easing the compliance burden. Another GRC focused fintech is the Cape Town-based firm Yue Diligence, which provides a platform to automate the due diligence process for investors seeking to finance entrepreneurs. This fintech offers a web-based tool which provides a structured framework to guide investors and entrepreneurs through the due diligence process for investment/fundraising.

In Cluster 4, Microfinance and Crowdfunding, many fintechs also selected the "Financial Education and Literacy" classification. One example, Crowdsunite, based in New York, is a review site for crowdfunding platforms which aims to educate potential users. The firm seeks to add value by providing guidance to those entrepreneurs seeking to run a successful funding campaign and so provides advice and access to experts as well as organizing classes and events. For investors, the site reviews fundraising campaigns and provides tools to analyze investment outcomes. Similarly, All Street, based in London, provides reports conducted by industry experts on equity and debt based crowdfunding projects for investors.

Liquidity Forecasting and Reporting. Many fintechs within Cluster 5 focused on helping organizations become more efficient in managing their cash and liquidity classification. One such example is DiscoverEdge, which allows banks to provide their commercial customers with cloud-based cash forecasting and working capital management applications through applying advanced analytics.

Data Governance and Privacy. Some fintechs in Cluster 6 were offering technologies to assist with the handling and use of private data to enhance and personalize traditional banking services. For example, Privatar in London allows organizations to analyze large data sets without breaching data privacy regulations. This provides a means for organizations to mine, use, share and trade data containing personal or confidential information. By doing so, they may broaden their use of existing data sets. The software increases data security and reduces the risk of data misuse, unintended or otherwise. It also reduces "missed opportunities" by allowing firms to anonymize and mine data sets and so extract maximum benefit from sensitive data assets. These techniques might otherwise have been impossible due to privacy regulations. Use-cases of Privatar's technology include customer analytics 
and marketing, system testing on datasets without re-identification risk, safe sharing of datasets for innovation and anonymization of data for cloud processing.

Another example is Digi.me which offers software that allows banks and retailers access to regulated personal data without causing compliance breaches. Digi.me aggregates all an individual's personal data, otherwise spread over the internet, into a private library that the user owns and controls. Digi.me allows banks to facilitate the personalization of online experiences to increase brand loyalty and target service products based on new combinations of personal data. This is achieved by firms requesting "permission access" to the consumer's Digi.me library.

E-commerce Financial Service Aggregators. Similarly, firms in Cluster 6 adopted customercentric strategies. These fintechs are able to collate an enormous amount of data regarding spending habits and intentions and so there exists a potential to leverage this data for cross-selling purposes through e-commerce. An example is the previously-discussed MaxMyInterest. A further example is Dyme, based in San Francisco, which focuses on the products and service offerings to which users aspire (e.g., vacations, weddings, Christmas gifts, etc.), and provides users with savings tools to help them obtain the item without getting into debt. Once an item has been identified, Dyme finds the user the best available deal through its relationship with retailers and offers its user base exclusive offers.

\subsection{Component Innovations}

Big Data and Artificial Intelligence. The third strand of analysis addresses technological innovations, which act as building blocks for the other two elements of the financial technology ecosystem. Firms in each of the six clusters identified which classifications related to the four Component innovation types and so each of the four innovation types were significantly present in all six clusters. By far, the most prevalent of these was the "Big Data and Artificial Intelligence" classification. Its selection by many firms in Cluster 2 reflects the use of business intelligence, analytics, data mining, and machine learning to guide and improve investment decision making, for example. Machine learning algorithms review vast amounts of data to make predictions and recognize patterns that can lead to the decision. We found that many of the firms in this cluster use these technologies to automate the investment decision-making process. One example is Stockspot. 
Analytics are traditionally utilized by financial incumbents to help understand creditworthiness and so through advanced uses of these technologies, understanding of default risk has evolved. Correspondingly, the most prevalent Component innovation underpinning credit and finance-related Services, Cluster 3, is also "Big Data and Artificial Intelligence." The case of Trusting Social illustrates how the scope of analytics used to assess creditworthiness has widened to include social media and mobile phone data. Indeed, fintechs utilizing advanced analytics to help financial incumbents better understand credit risk represent a significant element of the cluster. Within this cluster, we also observe how analytics are underpinning GRC innovations (e.g., Percentile).

Firms engaged in the provision of New Banking Services in Cluster 5 may use analytics to enhance liquidity forecasting and reporting capabilities (e.g., DiscoverEdge), as well as to enhance customer experience and develop loyalty. For example, $X$ Ware 42 utilizes analytics to manage the transfer of electronic receipts. Their software allows banks to provide online banking customers with additional information regarding their purchases by amending their statements to include information such as receipts, addresses, opening hours, service numbers and other details about retailers. This gives customers a more holistic picture of their purchases while allowing banks and partner retailers to use analytics to offer personalized discounts and encourage further transactions. Analytics also underpin approaches to leveraging personal data to create customer-centric service offerings while simultaneously remaining attentive to data privacy regulations (e.g., Digi.me and Privatar). The use of analytics to facilitate customer-centric strategies was also prevalent amongst firms engaged in delivering Personalized Financial Management services in this cluster. Often analytics are used to match users with the best financial products and services resulting in the automated movement of funds, or they are used to predict spending habits and offer relevant advice (e.g., Debitize or Dyme).

Messaging, Blockchain and DLT. Firms offering payments related innovations, often draw upon communication protocols, networks and digital cryptocurrencies to facilitate new business models. For example, Bitspark illustrates the use of crypto-currencies to facilitate faster and more efficient remittance services, while Coinjar offers a digital multi-currency wallet which also allows users to store, spend, and accept bitcoins, and to make P2P payments. Furthermore, DLT and messaging protocols underpin infrastructures for the clearing and settlement of transactions (e.g., Hyperledger). 
Cybersecurity and Identity Management Technology. Online fraud and hacking constitute an existential threat to fintechs because if innovations and underpinning technologies are not trusted they will not be used. Payment fintechs therefore adopt innovative approaches to maintaining security. For example, Token uses tokenization technologies, which substitute the direct use of sensitive financial data with identifying tokens and so isolate and protect consumers' financial data. The use of tokens allows sensitive information to be more readily reused across numerous transactions rather than having to be reentered and encrypted. This quickens the execution of transactions. We found, the "Cybersecurity and Identity Management Technology" classification was also self-selected by many fintechs. A further example is Sedicii of Ireland, which protects anonymity while providing passwords and identity verification. The software provides control to users of passwords and allows resetting and time-limited use while authenticating identity. The product is free to consumers but is offered by license or a cloud-based transaction-based model for enterprises. The business facilitates KYC and anti-money laundering protocols without compromising privacy.

Cloud Banking and Back-Office Technology. This classification was unsurprisingly found to be most present within New Banking Services, Cluster 5. One example of a firm which offers such technology is Vancouver based Zafin. In common with other firms in this cluster, Zafin focuses on personalizing the banking experience and provides back-office software to online banks to enable them to become more customer-centric. Their software integrates with the bank's core banking system to provide a 360-degree view of the bank's customers across geographies and lines of business. This enables banks to respond to customer and market demands quickly, release new products, enhance revenue and meet regulatory requirements. Berlin-based Mambu is another company that provides cloud software-as-a-service core banking systems for deposit and lending services. The aim is to allow challenger banks and incumbents to quickly bring new products and services to market without the time consuming and cost heavy hindrance of updating and integrating numerous core banking and legacy systems. 


\section{DISCUSSION: INNOVATIVE MECHANISMS AND VALUE CREATION STRATEGIES}

\subsection{Mechanisms for Competing and Cooperating}

Figure 2 outlines the relationships we defined and illustrates how incumbents and fintech start-ups may be consumers, collaborators and competitors to one another perhaps concurrently.

\section{INSERT FIGURE 2 HERE}

For example, a payments fintech offering an inclusive payment platform across different channels to merchants may also cooperate with an incumbent to develop Service innovations through open banking APIs. The fintech may also be paying to utilize the incumbent's infrastructure while the incumbent is developing its own competing platform. This scenario reflects the ways in which fintechs and incumbents' interests are becoming more common, entangled and interwoven, while they simultaneously compete. As access to financial information across fintech firms and incumbents increases, related innovations are restructuring information flows creating new forms of competition and cooperation. Through our analysis of the Innotribe dataset, we derived five innovative mechanisms by which financial information is becoming restructured through technology. Our findings show how fintech firms are altering long-established, and embedded banking models through mechanisms of disintermediation, extension of access, hybridization, financialization and personalization, thereby offering new forms of value creation through restructuring and coordinating the flow of financial information.

Disintermediation is one mechanism by which institutionalized models for competition and cooperation are becoming challenged and reimagined. In prior work, disintermediation has been defined as the ability of customers to interact online and directly with primary suppliers of services or products, without requiring the services of an intermediary who was previously essential to the transaction. Conversely, intermediation addresses the insertion of a new entity between buyer and seller [42]. Much of the current financial services value chain is arranged around the role played by financial intermediaries, as conduits of financial information between capital-seeking entrepreneurs and investors or between savers and borrowers. Analysis of the Innotribe dataset revealed many examples of financial information restructuring through combinations of technological innovations which ena- 
ble the insertion of a new intermediary or the bypassing of an existing one. One example of a competitive mechanism of disintermediation is the use of cryptocurrencies by Bitspark to transfer payments without the need for legacy banking networks and payment systems. However, we also find disintermediation mechanisms employed to foster cooperative strategies. For example, Madfoo3at.com has positioned the firm to act as a collaborative intermediary among utility companies, banks and consumers to digitize bill payments and create value for all parties. Examples of fintech start-ups which use disintermediation to foster cooperation are rarer as the act of bypassing an entity is not inherently cooperative. However, Digi.me is one such example. They disintermediate traditional data gathering and marketing firms, such as Google, by facilitating cooperation between incumbent banks and individuals to leverage the use of personal data, while giving individuals greater control. In this way, they are acting to intermediate between individuals and banks whilst simultaneously disintermediating traditional data gatherers and infomediaries.

Extension of access is the second mechanism we observe and refers to the provision of technological innovations to restructure the flow of financial information to engage new participants in financial services and markets. Firms which identified with the Crowdfunding and Microfinance classification, Cluster 4, are good examples of fintech start-ups employing technology to compete with incumbents engaged in traditional lending activities. These fintechs extend access to more affordable credit services for workers (e.g., ZAQ Finance and Creditable) or small businesses (e.g., Lulalend and Kickfurther), as well as extending access to investors who may not normally have the opportunity to fund entrepreneurial activities in the way venture capital firms or banks do. Through advanced analytics and artificial intelligence, fintech start-ups may reduce the costs of investment services and thereby extend access to those who find the costs associated with a human financial advisor prohibitive (e.g., Stockspot). Activa is an example of a fintech start-up which seeks to cooperate with incumbents through extending access to financial information. They integrate their technology with an incumbent's core banking system to facilitate a wider range of payments channels and to extend payment options to the banks' corporate customers.

Financialization is the third mechanism derived from the Innotribe dataset and refers to the innovative emulation of financial services to create new forms of competition and collaboration [46]. 
We observe how, through technological innovations, fintechs mimic the structure and discipline of financial markets and so seek to financialize information flows and channel them in ways which create new forms of value. For example, crowdsourcing platforms emulate stock markets and the provision of bid and ask prices for new equity or debt-based assets. Furthermore, they compete with traditional forms of entrepreneurial financing. Fintech firms may seek to refinance existing financial contracts to facilitate while-labeled products and so allow greater customer flexibility. Moreover, they cultivate closer and longer lasting relationships enabling future sales opportunities (e.g., Premfina). Other fintechs have sought to monetize and collectively finance analyst reports to enhance investment decision-making (e.g., Stockview) or monetize personal data (e.g., Digi.me). Other fintechs directly or indirectly cooperate with incumbents, to provide merchants the capability to provide white-label coupons or loyalty points which consumers can exchange for products and services as a substitute for cash. In this way, merchants can foster customer loyalty and encourage repeat sales (e.g., Digicash Payment).

Hybridization is the fourth mechanism we observe in our population of fintech firms. This mechanism refers to the purposeful cohesion of business models, products and services which were previously separated, to facilitate innovative services. Thus, entrepreneurs blend and re-channel financial information across traditional boundaries of financial activities and create value by bridging divergent elements of the value chain. For example, to compete with incumbent remittance infrastructure providers Bitspark hybridizes a cryptocurrency exchange, a remittance service and business-tobusiness payments that would otherwise be regarded as discrete services using different technical platforms. Stockpot hybridizes gamification and simulation services with investment and portfolio management information, to compete with incumbent asset management and financial advisory firms. Coinjar provides an example of how hybridized forms of financial information may underpin collaboration between fintechs and incumbents. By cooperating and collaborating with Australian Stock Exchange-listed EML Payments, Coinjar offer a prepaid debit card that allows users to spend their bitcoins on everyday purchases. In addition to bitcoin, Coinjar's e-wallet can also hold different major currencies, for example, USD, GBP, AUD and EUR. This allows for the hedging of bitcoin price 
volatility against these currencies. In this way, Coinjar synthesizes mobile payments, e-wallets, currency hedging and cryptocurrency technologies to extend the value creation capabilities of each of these innovations.

Personalization is the fifth mechanism we derived from our analysis. Many of the customercentric strategies we observed were cooperative in nature. Value is created through merging and analyzing different streams of financial information flows to create a personalized service. To capture, collate and analyze consumers' personal data fintech firms often collaborate with incumbents to source different flows of financial information (e.g., mortgage payments, insurance premiums, credit cards and checking account transactions) and then amalgamate them to create new forms of value (e.g., Budget Insight). A customer-centric strategy may also be realized through the cooperative integration of fintech systems with incumbents' back-office systems to provide customer-centric banking services (e.g., Zaffin) Another identified strategy involves providing individuals with enhanced capabilities to manage their personal finances (e.g., Debitize) and maximize benefits from the accounts they hold (e.g., MaxMyInterest) or leverage personal data to cross-sell and up-sell through targeted advertising (e.g., Xware 42). Regulations which restrict the sharing and utilization of personal data may create barriers to such innovations and impact the viability of related services. As a response to these challenges, fintechs enable personal financial data to be leveraged in a compliant manner, by anonymization or passing control back to the consumer (e.g., Privatar or Digi.me). Finally, the ability to personalize investment (e.g., Stockspot) and savings strategies (e.g., Dyme) to create specific outcomes and achieve goals position such fintechs in direct competition with traditional purveyors of financial advice.

\subsection{Fintech Value-Creation Strategies}

The mechanisms we outline are not mutually exclusive. Instead, we observe how they are mutually reinforcing and interdependent. For example, Stockspot both disintermediates incumbent financial advisors while extending access by reducing barriers of entry to financial markets. Hybridization and financialize are also linked as firms hybridize practices and methods borrowed from financial markets, such as risk management, hedging, market making, with practices from other industries, for 
example, gamification. In so doing, this may remove barriers, extend access and increase financial inclusion. Consequently, fintech strategies of value creation are multi-faceted and considerably nuanced in their application. A contribution is made by studying how these technology-supported mechanisms create value for fintechs, consumers and incumbents. Table 6 illustrates the value creation strategies employed and their relationships with the clusters, mechanisms and core services inductively derived from the Innotribe dataset.

\section{INSERT TABLE 6 ABOUT HERE}

\section{CONCLUSION}

\subsection{Contributions}

This study provides coherence and develops our understanding of the highly complex and nuanced global fintech landscape based, for the first time, on empirical studies of fintechs from around the globe. Through cluster analysis and numerous case studies we have been able to develop a model for classifying the characteristics of the fintech landscape and so a step has been taken towards a much-needed common nomenclature for understanding this phenomenon. However, we must acknowledge that a fully robust nomenclature for describing all possible forms of financial innovation is some way off not least as this field remains in churn as fintechs inevitably fail and new innovations are continuously introduced.

We provide insight into the ways in which fintechs are developing new offerings through the symbiotic syntheses of Service, Business Infrastructure and Component technological innovation types. We offer case-based evidence of innovative combinations of these innovation types and link them to ways in which these technologies are creating mechanisms which restructure, reconstitute and redirect flows of financial information through competitive and cooperative mechanisms. Our analysis allows us to define and outline illustrative strategies by which the mechanisms we identify create value across core service areas. As reflected in our multi-disciplinary review of prior work, these mechanisms are present to some degree, although often referred to in different terms within various streams of management, information systems, strategy and finance literature. However, our contribu- 
tion lies in showing how these mechanisms apply to the fintech landscape and related contested markets and innovation spaces and how they influence and shape value creation strategies. The application of these ideas to this context therefore, further demonstrates the robustness of these constructs in understanding new forms of innovation.

\subsection{Implications for Policy and Practice}

The targeted funding levels for capital investments reported by the 2015 Innotribe participants were in excess of $\$ 250$ million, see Table 2. Yet, the overall value of the Innotribe experience and our interpretations and classifications of it extends beyond the individual entrepreneur or participating company. Although historic perceptions of disruptive innovation would suggest that incumbent organizations would adopt protective strategies, the Innotribe experience and our related analysis of it provides insight into how new innovations and related entrepreneurial activities can be fostered and facilitated by the intervention of incumbents such as SWIFT. By classifying the types of innovations that are emerging and how they compete and collaborate a clearer perspective emerges of the skillsets and knowledgebase needed to protect and foster innovations in this sector (e.g., financial modelling, blockchain, data analytics) as well as the areas of national infrastructures which require investment to ensure innovations can flourish (e.g., cyber-defense, broadband and mobile networks).

This study provides individuals seeking to understand the fintech world, perhaps for entrepreneurial, investment or governmental purposes, with a useful point of departure. Our analysis provides insight into the future direction of an industry which many governments deem as pivotal to economic stability and prosperity. Indeed, in the U.K. and U.S., governmental attempts to classify new digital businesses, for business registration and tax purposes have proved problematic. If governments do not have a holistic view of the fintech landscape, they may not fully understand the regulatory implications of the introduction of new innovations to an industry which has remained static for many years in terms of disruptive innovation and whose regulatory structures reflect this.

Our work shows how fintech innovations are radically changing financial markets in ways which may render current regulations outdated and ineffective in some cases. Policy-makers must find a delicate balance between protecting consumers and so outlawing innovations which may create unfamiliar consequences or fostering innovations which may bring considerable societal benefits but 
which may also create uncertain outcomes for consumers. Such benefits include building the country's innovative capabilities, attracting investment in new business, higher employment rates and improved global positioning in financial services. A deeper understanding of fintech innovations in terms in of core Services, supporting Business Infrastructures and underlying Components and the new means of competition and cooperation they create, may help policy-makers navigate an appropriate course. Clarity of the fintech landscape supports the development of regulatory frameworks and tax incentives that encourage both investors and entrepreneurs to continue to innovate at an accelerated pace, while ensuring consumer protection and the introduction of unacceptable levels of systemic risks to economic systems are prevented.

\subsection{Limitations and Concluding Comments}

Research of this sort is always restricted by the qualities of the evidence available and the breadth of the investigation possible when the data was not collected for the purposes of scientific inquiry. We should acknowledge that the self-selection of classifications by fintechs may have created some anomalies in the data. We believe any anomalies have been addressed through working with SWIFT to refine the classifications and validate the membership of each cluster and that the relatively small impact of a few displaced cases was outweighed by obtaining a large dataset on fintechs classified by the entrepreneurial teams who founded the start-ups.

Furthermore, while we observe how the presence of these mechanisms and other characteristics are employed in entrepreneurial attempts at value creation we are yet unable to tell if they are useful indicators for the long-term success of fintech firms. Indeed, it is too early to review the Innotribe dataset to establish which fintechs achieved success in terms of further funding, acquisitions or longterm dominance of specific niches and sectors. Future work may revisit the Innotribe dataset to explore the longevity and success of fintechs adopting mechanisms of competition and cooperation. 


\section{REFERENCES}

[1] Clemons, E.K., and Weber, B.W. London's Big Bang: A case study of information technology, competitive impact, and organizational change. J. Mgmt. Info. Sys. 6, 4 (Spring 1990), 41-60.

[2] Adner, R., and Kapoor, R. Value creation in innovation ecosystems: How the structure of technological interdependence affects firm performance in new technology generations. Strategic Mgmt. J. 31, 3 (March 2010), 306-333.

[3] Adomavicius, G.; Bockstedt, J.C.; Gupta, A.; and Kauffman, R.J. Technology roles and paths of influence in an ecosystem model of technology evolution. Info. Tech. Mgmt. 8, 2 (June 2007), 185-202.

[4] Adomavicius, G.; Bockstedt, J.C.; Gupta, A.; and Kauffman, R.J. Making sense of technology trends in the information technology landscape: A design science approach. MIS Qtrly. 32, 4 (December 2008), 779-809.

[5] Akerlof, G.; Spence, A.; and Stiglitz, J. Markets with asymmetric information. Nobel Prize in Economics, Sverige Rijksbank, Stockholm, Sweden, 2001.

[6] Au, Y.A., and Kauffman, R.J. The economics of mobile payments: Understanding stakeholder issues for an emerging financial technology application. Elec. Comm. Res. Appl. 7, 2 (Summer 2008), 141-164.

[7] Bamberger, K.A. Technologies of compliance: Risk and regulation in a digital age. Texas Law Review, 88, 4 (2010), 669-739.

[8] Benbasat, I.; Goldstein, D.K.; and Mead, M. The case research strategy in studies of information systems. MIS Qtrly. 11,3 (September 1987), 369-386.

[9] Bruton, G.; Khavul, S.; Siegel, D.; and Wright, M. New financial alternatives in seeding entrepreneurship: Microfinance, crowdfunding, and peer-to-peer innovations. Entrepreneurship Theor. Prac. 39, 1 (January 2015), 9-26.10.

[10] Clemons, E.K.; Dewan, R.M.; Kauffman, R.J.; and Weber, T.A. Understanding the information-based transformation of strategy and society. J. Mgmt. Info. Sys. 34, 2 (August 2017), 425-45611.

[11] Cumming, D.J., and Schwienbacher, A. Fintech Venture Capital (May 7, 2016). Working paper, Social Science Research Network. Available at https://papers.ssrn.com/sol3/papers.cfm?abstract_id=2784797.

[12] Dahlberg, T.; Guo, J.; and Ondrus, J. A critical review of mobile payment research. Elec. Comm. Res. Appl. 14, 5 (September 2015), 265-284.

[13] de Reuver, M.; Verschuur, E.; Nikayin, F.; Cerpa, N; and Bouwman, H. Collective action for mobile payment platforms: A case study on collaboration issues between banks and telecom operators. Elec. Comm. Res. Appl. 14, 5 (September 2015), 331-344.

[14] Denzin, N.K., and Lincoln, Y.S. The Sage Handbook of Qualitative Research, Thousand Oaks, CA: Sage, 2005.

[15] Drummer, D.; Feuerriegel, S.; and Neumann, D. Crossing the next frontier: The role of ICT in driving the financialization of credit. J. Info. Tech. 32, 3 (September 2017) , 218-233.

[16] Dunbar, R.L., and Starbuck, W.H. Learning to design organizations and learning from designing them. Org. Sci. 17, 2 (April 2006), 171-178.

[17] Eisenhardt, K.M. Building theories from case study research. Acad. Mgmt. Rev. 14, 4 (October 1989), 532-550.

[18] Everitt, B.S.; Landau, S.; Leese, M.; and Stahl, D. Cluster Analysis, $5^{\text {th }}$ Ed. Chichester, UK: John Wiley, 2011.

[19] Fleming, L., and Sorenson, O. Financing by and for the masses. California Mgmt. Rev. 58, 2 (Winter 2016), 5-19.

[20] Gioia, D.A.; Corley, K.G.; and Hamilton, A.L. Seeking qualitative rigor in inductive research notes on the Gioia methodology. Org. Res. Methods 16, 1 (January 2013), 15-31.

[21] Gomber, P., Koch, J.-A., and Siering, M. Digital finance and fintech: Current research and future research directions. J. Bus. Econ. (February 2017), 1-44.

[22] Gozman, D., and Currie, W. The role of investment management systems in regulatory compliance: A post-financial crisis study of displacement mechanisms. J. Info. Tech. 29, 1 (March 2014), 44-58.

[23] Gozman, D.; Currie, W.; and Seddon, J. The role of big data in governance: A regulatory and legal perspective of analytics in global financial services. Working paper, SWIFT Institute, London, December 2015.

[24] Greenwald, B.C., and Stiglitz, J.E. Asymmetric information and the new theory of the firm: Financial constraints and risk behavior. Working paper, National Bureau of Economic Research, Cambridge, MA, 1994.

[25] Hatzakis, E.D.M.; Nair, S.K.; and Pinedo, M. Operations in financial services - An overview. Prod. Oper. Mgmt. 19, 6 (November 2010), 633-664.

[26] Hedman, J., and Henningsson, S. Competition and collaboration shaping the digital payment infrastructure. In Proc. 14th Intl. Conf. Elec. Comm., New York: ACM Press, 2012, 178-185. 
[27] Hedman, J., and Henningsson, S. The new normal: Market cooperation in the mobile payments ecosystem. Elec. Comm. Res. Appl. 14, 5 (September 2015), 305-318.

[28] Henderson, J.C., and Lentz, C.M.A. Learning, working, and innovation: A case study in the insurance industry. J. Mgmt. Info. Sys. 12, 3 (December 1995), 43-64.

[29] SWIFT Institute. Startup challenge. Innotribe Competition Publication, London, UK, 2016.

[30] Kauffman, R.J.; Liu, J.; and Ma, D. Innovations in financial IS and technology ecosystems: Highfrequency trading in the equity market. Tech. Forecast. Soc. Change, (October 2015), 339-354.

[31] Kauffman, R.J.; Ma, D.; Shang, R.; Huang, J.; and Yang, Y. On the financification of cloud computing: An agenda for pricing and service delivery mechanism design research. Intl. J. Cloud Com. 2,1 (January 2014) 1-24.

[32] Khiaonarong, T., and Liebenau, J. Banking on Innovation: Modernization of Payment Systems. Contributions to Economic Series, Heidelberg, Germany: Physica-Verlag, 2009.

[33] Larsen, K.R. A taxonomy of antecedents of information systems success: Variable analysis studies. $J$. Mgmt. Info. Sys. 20, 2 (Fall 2003), 169-246.

[34] Leu, F.Y.; Huang, Y.L.; and Wang, S.M. A Secure m-commerce system based on credit card transaction. Elec. Comm. Res. Appl. 14, 5 (September 2015), 351-360.

[35] Liu, J.; Kauffman, R.; and Ma, D. Competition, cooperation and regulation: Understanding the evolution of the mobile payments technology ecosystem. Elec. Comm. Res. Appl. 14,5 (September 2015), 372-391.

[36] Ma, T., and McGroarty, F. Social machines: How recent technological advances have aided financialisation. J. Info. Tech. 32, 3 (September 2017), 234-250.

[37] Miles, M.B., and Huberman, A.M. Qualitative Data Analysis: A Sourcebook of New Methods. Thousand Oaks, CA: Sage, 1984.

[38] Milligan, G.W., and Mahajan, V. A note on procedures for testing the quality of a clustering of a set of objects. Dec. Sci. 11, 4 (October 1980), 669-677.

[39] Polasik, M.; Piotrowska, A.I.; Wisniewski, T.P.; Kotkowski, R.; and Lightfoot, G. Price fluctuations and the use of bitcoin: An empirical inquiry. Intl J. Elec. Comm. 20, 1 (August 2015), 9-49.

[40] Reck, M. The formal and systematic specification of market structures and trading services. J. Mgmt. Info. Sys. 15, 2 (Fall 1998), 9-21.

[41] Schwartz, R.A.; Sipress, G.M.; and Weber, B.W. Mastering the Art of Equity Trading through Simulation. Hoboken, NJ: John Wiley, 2010.

[42] Sen, R., and King, R.C. Revisit the debate on intermediation, disintermediation and reintermediation due to E-commerce. Elec. Mkts 13, 2 (January 2003), 153-162.

[43] Shane, B.; Fry, M.; and Toro, R. The design of an investment portfolio selection decision support system using two expert systems and a consulting system. J. Mgmt. Info. Sys. 3, 4 (Spring 1987), 79-92.

[44] Siering, M.; Clapham, B.; Engel, O.; and Gomber, P. A taxonomy of financial market manipulations: Establishing trust and market integrity in the financialized economy through automated fraud detection. $J$. Info. Tech. 32, 3 (September 2017), 1-19.

[45] Uprichard, E. Introducing cluster analysis: What can it teach us about the case? In D. Byrne and C.C. Ragin (eds.), The SAGE Handbook of Case-Based Methods, London: Sage, 2009, pp. 260-268.

[46] Van der Zwan, N. Making sense of financialization. Socio-Economic Rev. 12, 1 (January 2014), 99-129.

[47] Williams, J.W. Regulatory technologies, risky subjects, and financial boundaries: Governing 'fraud' in the financial markets. Acct., Org. Soc. 38, 6 (August 2013), 544-558.

[48] Zachariadis, M., and Ozcan, P. The API economy and digital transformation in financial services: The case of open banking. SWIFT Institute, London, UK, 2016.

[49] Zott, C.; Amit, R.; and Massa, L. The business model: Recent developments and future research. J. Mgmt 37, 4 (May 2011), 1019-1042.

[50] Zuboff, S. In the Age of the Smart Machine: The Future of Work and Power. New York: Basic Books, 1988. 


\section{TABLES}

\begin{tabular}{|l|l|}
\hline \multicolumn{2}{|c|}{ Cluster Analysis } \\
\hline Application & $\begin{array}{l}\text { - Firms select } 3 \text { out } 17 \text { classifications to describe their business focus } \\
\text { - Classifications support clustering firms for core Service innovations } \\
\text { - Also related Business Infrastructure and Component innovations }\end{array}$ \\
\hline \multicolumn{2}{|c|}{ Case Analysis } \\
\hline Registration & $\begin{array}{l}\text { - Firm HQ location; showcase events firm preferred to present } \\
\text { - Details of firm's websites, Twitter accounts }\end{array}$ \\
\hline Application & $\begin{array}{l}\text { - Info on how firm's innovation is of value to SWIFT, its members and their customers } \\
\text { - \# staff, gender split, investment level, revenue received, \# customers }\end{array}$ \\
\hline Pitch slides & $\begin{array}{l}\text { - Froduct description } \\
\text { - Fech solution details, related services, business model, commercial viability }\end{array}$ \\
\hline Pitch video & - Assessment of ability to execute, competitive advantage, funding plans, firm's core team \\
\hline $\begin{array}{l}\text { Showcase } \\
\text { Video }\end{array}$ & $\begin{array}{l}\text { - For presentation at final competition } \\
\text { - Guidance for elevator pitch, problem; solution; market size, business model } \\
\text { - Also proprietary technology, competition, marketing plan, team, money }\end{array}$ \\
\hline Website & - Links to websites; details of their products, services, business sectors of operation \\
\hline Press & - Supplemental press commentaries and analyst reports on firms and their innovations \\
\hline
\end{tabular}

Table 1: Data Sources

\begin{tabular}{|c|c|}
\hline \multicolumn{2}{|c|}{ Staffing } \\
\hline $\begin{array}{l}\text { - Number of Staff (Average) } \\
\text { - Staff Diversity (Percentage of Male Staff) }\end{array}$ & $\begin{array}{l}14 \\
75 \%\end{array}$ \\
\hline \multicolumn{2}{|c|}{ Customers, Revenue and Investment } \\
\hline $\begin{array}{l}\text { - Number of Customers (Average) } \\
\text { - Projected Revenue - Year } 1 \text { (Average) } \\
\text { - Total Projected Revenue - Year } 1 \\
\text { - Projected Investment - Year } 1 \text { (Average) } \\
\text { - Total Projected Investment - Year } 1\end{array}$ & $\begin{array}{l}35,770 \\
\$ 3,639,336 \\
\$ 429,441,598 \\
\$ 2,107,576 \\
\$ 250,801,576\end{array}$ \\
\hline
\end{tabular}

Table 2: Descriptive Stats. for the SWIFT Innotribe Competition 2015.

Note: These variables were not collected by SWIFT in 2013 and 2014. 


\begin{tabular}{|lcl|}
\multicolumn{1}{c}{$\begin{array}{c}\text { Innovation Classifications } \\
\text { (clustering input variables) }\end{array}$} & Innovation Types & \multicolumn{1}{c|}{$\begin{array}{c}\text { SWIFT } \\
\text { Classifications }\end{array}$} \\
\hline Payments & Services & B2B, B2C, P2P, mobile payments, remittances \\
Investment and Asset Mgmt & Services & Wealth and portfolio management \\
Finance and Credit Mgmt & Services & Traditional lending and credit \\
Microfinance and Crowdfunding & Services & Crowdfunding, microfinance and P2P Loans \\
New Banking & Services & Digital banking, customer experience, distribution channels \\
Personal Financial Mgmt (PFM) & Services & PFM, vendor management, e-wallet, taxes, bills, invoices \\
\hline EC, Financial Service Aggregators & Bus Infrastructure & E-commerce cross-selling support \\
Merchant/Corp. Support & Bus Infrastructure & Support services for retail merchants and corporations \\
Financial Education and Literacy & Bus Infrastructure & Gamification and simulation to educate consumers \\
Clearing and Settlement & Bus Infrastructure & Settlement, continuous linked settlement \\
Governance, Risk, Compliance & Bus Infrastructure & Standards and regulation, policy mgmt risk, KYC, AML \\
Liquidity Forecasting and Reporting & Bus Infrastructure & Liquidity reporting and forecasting \\
Data Governance and Privacy & Bus Infrastructure & Identifiers, regulatory data, cross-references, data mgmt \\
\hline Big Data and AI & Components & Business intel, analytics, data mining, algos, data processing \\
Cybersecurity, Identity Mgmt Tech & Components & Cybersecurity, authentication, biometrics, data protection \\
Cloud Banking, Back-Office Tech & Components & Core banking systems records and workflow management \\
Messaging, Blockchain, DLT & Components & Communication protocols, cryptocurrencies, blockchain \\
\hline
\end{tabular}

Table 3: Classifying Fintech Innovations

\section{Bitspark}

- Founded in HK 2014: Bitcoin remittance payments

- Emerging markets and Asia have $£ 280$ bn, $40 \%$ by competing MTOs

- Banking software restrictive, limited currencies, withdrawal options, and country-pair connections - MTO must use several platforms for transfers

- Blockchain, bitcoin reduce MTO transaction costs

- Now partnered with local bank, innovators, investors

\section{Madfoo3.com}

- Jordan, for e-payments via government seed investment program, Oasis 5001, partnering with Central Bank - E-billing to replace cash in Mid East, N Africa - Services to banks, merchants for e-bill payments Banks, merchants register once for customer use

- Merchants pay fee per transaction

- Firm shares fees with banks, creating revenues

\section{Technology}

\begin{tabular}{l|l} 
- Web platform, mobile tech, blockchain with bitcoin & - Centralized e-bill presentation, payment services
\end{tabular}

- Increased speed and efficiency of transfers

- Cheaper than conventional transfer systems

- More competitive pricing

- Mobile phone, electric and water utility bills

- For real-time inquiry and payment, uses Internet, mobile, ATM, call center channels

- Lower fees, secure services

- No commissions for network providers, banks

- Mechanisms for cooperation

- Government subsidies for better payment infrastructure - Value comes from billing utilities

\section{Mechanisms of Competition and Cooperation}

- Disintermediating platform bypass for financial

- Hybridizes a cryptocurrency exchange

- Remittances, B2B payments use different platforms

- Payments transfer without banking networks

- Disintermediates payment systems with automation

- Bitcoin exchange cuts cash reserves for remittances

- Better volume, liquidity, spread and capacity
- Standard billing service for many participants

- Eliminates paper bills by post to customers

- Cuts out manual processing

- Supports regular reporting and error detection

- Shifts focus to allow more control by bill-payers

Table 4: Example of Case Template for the Payments Cluster (Cluster 1) 


\begin{tabular}{|c|c|c|c|c|c|c|}
\hline Cluster & Core Service & Business Infrastructure & \multicolumn{4}{|c|}{ Component } \\
\hline 1 & Payments & - Merchant/Corp. Support & \multirow{6}{*}{ 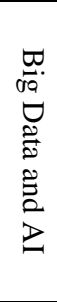 } & \multirow{6}{*}{ 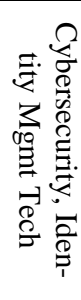 } & \multirow{6}{*}{ 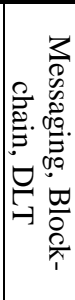 } & \multirow{6}{*}{ 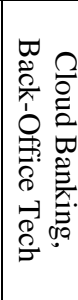 } \\
\hline 2 & Investment and Asset Mgmt & $\begin{array}{l}\text { - Financial Education and Literacy } \\
\text { - Clearing and Settlement }\end{array}$ & & & & \\
\hline 3 & Finance and Credit Mgmt & - Governance, Risk, Compliance & & & & \\
\hline 4 & Microfinance \& Crowdfunding & - Financial Education and Literacy & & & & \\
\hline 5 & New Banking & - Liquidity Forecasting and Reporting & & & & \\
\hline 6 & Personal Financial Mgmt & $\begin{array}{l}\text { - Data Governance and Privacy } \\
\text { - EC, Financial Service Aggregators }\end{array}$ & & & & \\
\hline
\end{tabular}

Table 5: Characteristics of the Fintech Landscape

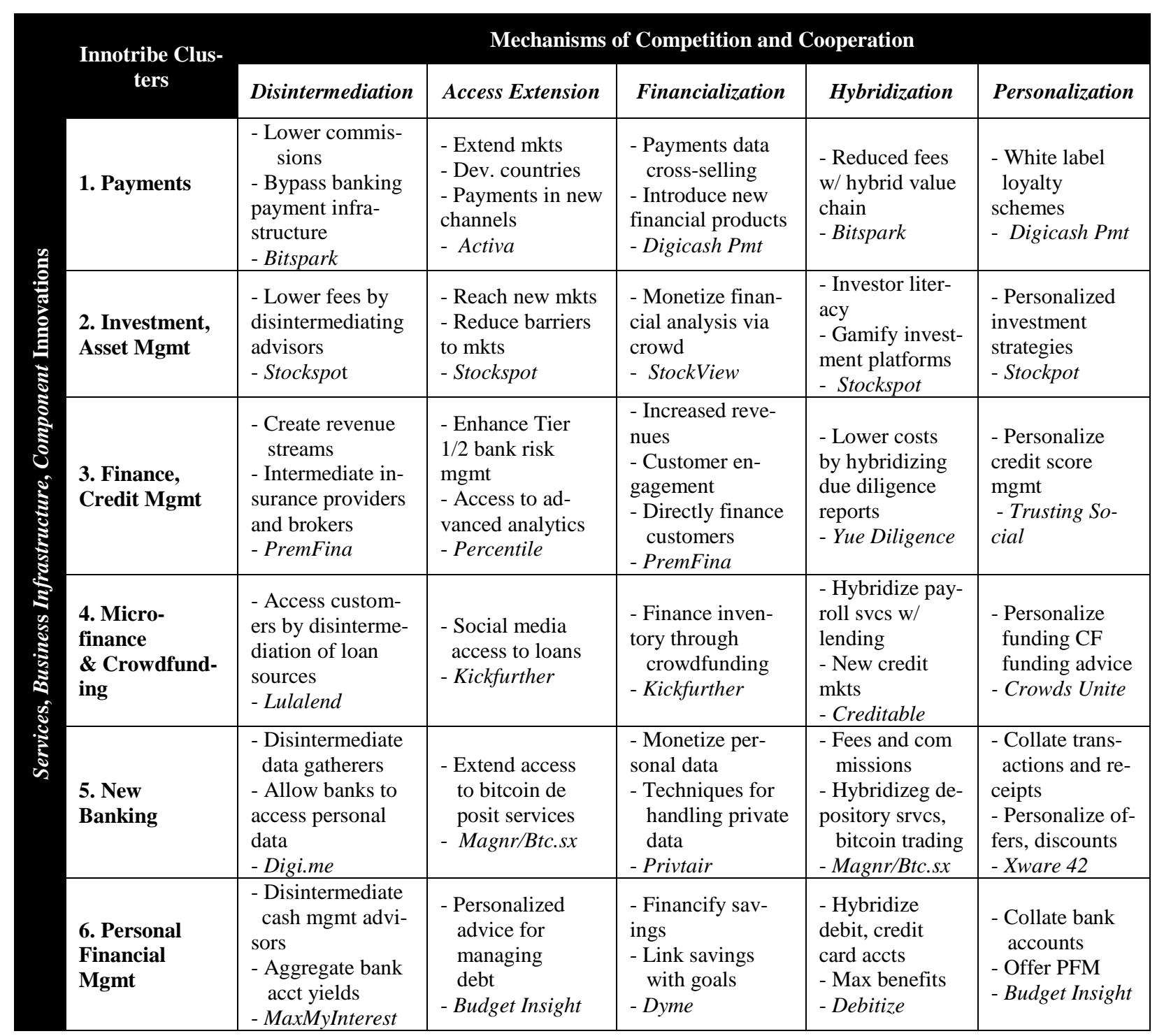

Table 6: Illustrative Strategies for Fintech Value Creation 


\section{FIGURES}

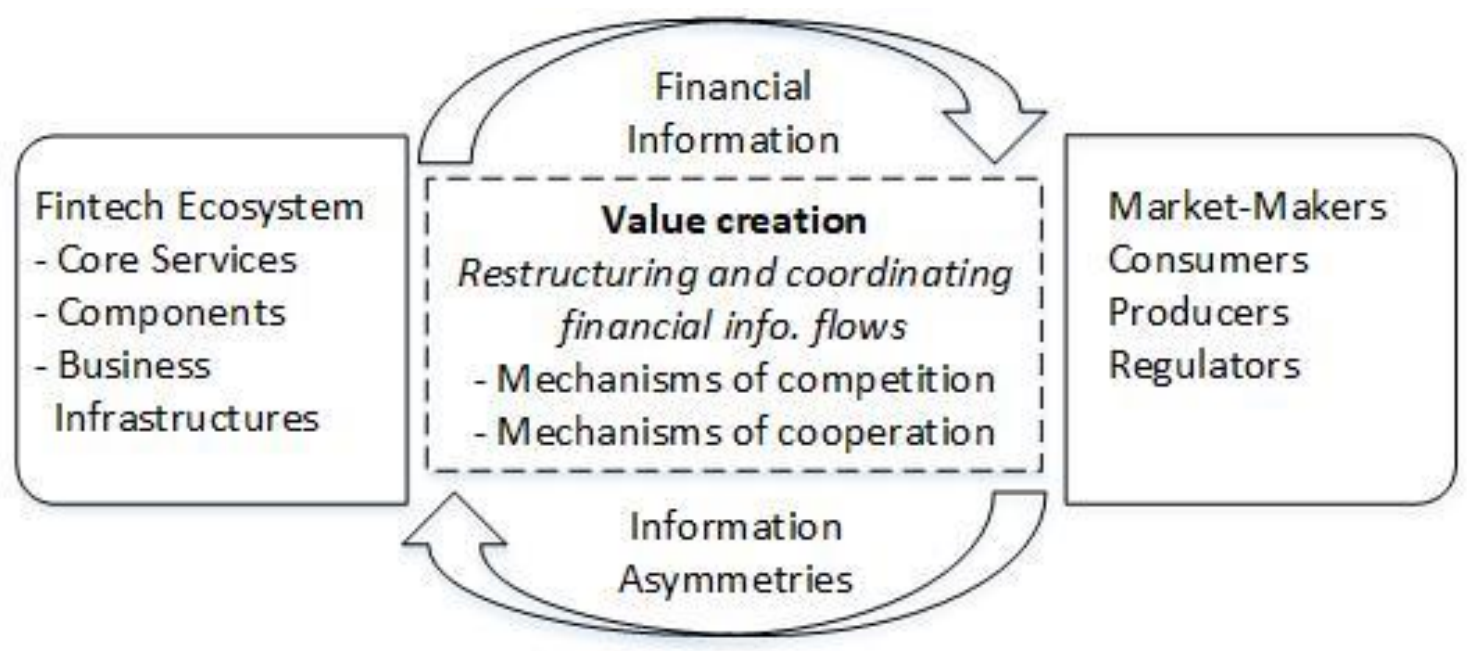

Figure 1: Conceptual Model of Fintech Innovation

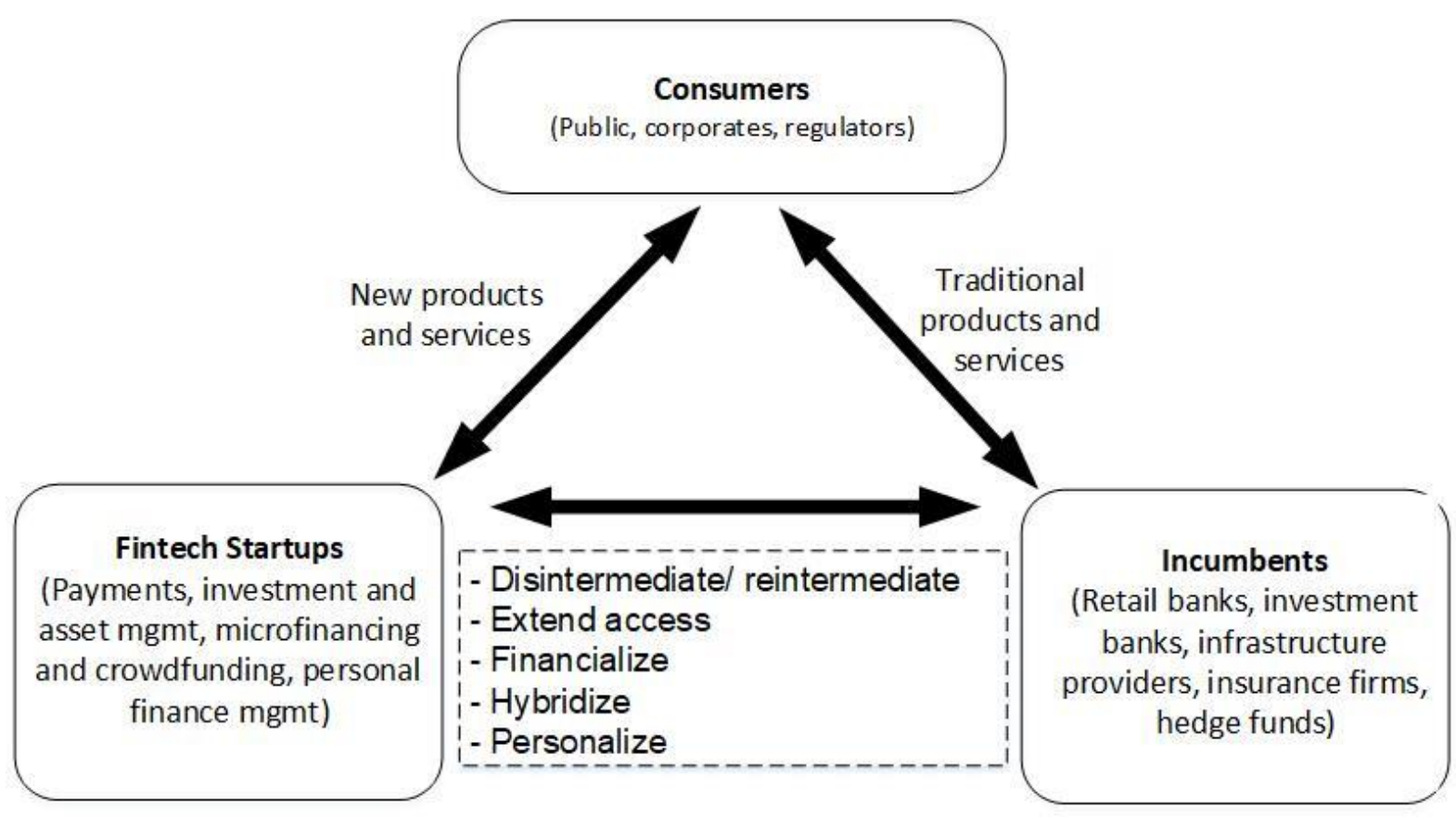

Figure 2: Connections Across the Fintech Landscape 